\title{
Literary motif of pain in the framework of cognitive narratology
}

\author{
I. O. Koliesnik
}

Kyiv National Linguistic University

Paper received 25.08.19; Revised 07.09.19; Accepted for publication 11.09.19.

\section{https://doi.org/10.31174/SEND-Ph2019-204VII60-11}

\begin{abstract}
This article investigates the literary motif of pain with regards to current findings of cognitive narratology and the philosophy of mind, used to highlight the conceptual nature of this phenomenon. Recurrent identifiable patterns of the said motif are likely, as this research suggests, to reveal not only its complicated internal structure in the narrative realization, but also serve as another compelling proof of the human mind operating in a pattern-recognition mode. The article expounds the above idea by presenting a case-study of E. Hemingway's "For Whom the Bell Tolls" in terms of the motif of pain.
\end{abstract}

Keywords: literary motif, cognitive narratology, pattern, narrative, pattern-recognition mode, pain.

Any perception of fictional or non-fictional textual artefacts is inevitably conditioned and, therefore, enabled by the readers' recognition and interpretation of themes, topics, and structures recurrent in a literary text.

Recent studies in cognitive neuroscience define mind and its primary activity as "pattern extractors/-ing" [3], with Gerald Edelman's claiming "the "primary mode" of thought to be a "pattern recognition' [4, p.103]. Ray Kurzweil also expressed a similar idea with his vision of a human brain model, imagined as a unified processing paradigm $[18$, p. 5, 7, 23] consisting of a hierarchy of ongoing self-organizing pattern routines. The mentioned paradigm construes probable future possible outcomes of a particular action that tailors in human ability to recognize a familiar object and situations [18, p. 29, 172, 31-32]. Such view has been supported in today's critical works on narrative that reveal how quick our mind is to identify a novel pattern [2], thus, shifting our perception of art "as a cognitive play with pattern" [4].

It is important to stress that the view on mind as expressed by Ray Kurzweil in his P.R.T.M., the acronym that stands for Pattern Recognition Theory of Mind, is not ground-breaking [18]. In the 1980s similar ideas of our brain wired to recognise and teach itself new patterns (part of which are strongly believed to be hereditary) emerged due to new theories in computer science and the invention of AI, specifically the one proposed by Jeff Hawkins and known as the Hierarchical Temporary Memory system [8]. The latter (HTMS) was also inspired by Kunihiko Fukushima introducing the neocognitron, a hierarchical artificial neural network that operates on multiple layers [6]. Taking every piece of this theoretical patchwork into account the topicality of this study of motif within the field of cognitive narratology yields further investigations of the role of patterns in literary text.

Due to the aforementioned reasons, today's research on the mind-narrative nexus is more relevant than ever and calls for diverse, fictional and nonfictional, digital and print, verbal corpora and a substantive body of methods of analysis. The mind-narrative nexus is the term coined by David Herman [9, p. 137-161] as well as its use in the view of "qualia" - the term used to refer to "the sense of "what it is like" for someone or something to have a particular experience" [p. 137]. David Herman differentiates two main lines of inquiry that the field of cognitive narratology investigates [10].

The first one involves an extensive research on narrative as a target of interpretation [10, p. 21-114]. The scholar's research focuses on the analysis of mental processes that enable a person's understanding of what the narrative is, consequently, letting the readers navigate "storyworlds" $[10$, p. 103] to the extent that ensures the smooth run of the interpretation process. The way interpreters' employ the author's provided set of characters involved, the temporal and spatial dimensions of the text and a functioning model of the mentioned characters' existential experience is also a part of the research. Conversely, the second approach does not exhibit an acute interest in the narrative itself, but rather sees it as a tool that triggers individual's meaningmaking faculties [10, p. 225-311], also known as semiosis [16, p. 28-42].

The question that motivates our research is where a literary motif belongs in the context of current studies. The identification of narrative representations of a literary motif as such, its constituents, a particular case of the motif of pain constitute the aim of this article.

Given the shift of attention to literary motifs and their components, one can hardly gauge the whole scope of studies conducted in this domain $[11 ; 5$, p. 47-49]. The notion of motif is investigated ubiquitously across linguistics, textual poetics and literary studies. The twofold view on the nature of motif can be summarized as i) "a motif is the concrete realisation of a fixed abstract idea, often spanning a complete narrative unit"; ii) "the motif is a moveable stock device that appears in many periods and genres" [23, p. 445-446].

A motif preserves its identity within the narrative paradigm, as well as across a wide variety of other narrative "stepping-stones", e.g. characters, actions, and settings. The content of a motif consists of participants (agents), action, locality, objects, temporal phases, and dispositions. Usually a motif is anchored to "a nuclear action sequence" [23, p. 445]. The latter "can take different forms and cover more than a single event" [22, p. 445]. Though, one might notice certain similarities between a motif and other moveable stock devices (themes and plot kernels), the initial impression of those being akin is most likely to be mendacious. Motif is a distinguishably different from other devices due to its "level of abstraction" (it is less abstract than a theme) and "preciseness of character and action" (presupposes a particular set of characters and a fixed action sequence unique to a given motif) [23, p. 446].

Verbal narratives often presuppose a narrator who is virtually responsible for the production of the narrative text or narrative discourse. From the literary text an interpreter construes the "storyworld" and action structure, the plot, 
which in itself is a manifestation of the fable of network of motifs - put differently, a complex system of interdependent relationships of enmity and friendship among multiple story motifs - of the story [5, p. 7]. Recurring motifs are encoded in a sign sequence, often that of the keywords. Nevertheless, this might not always be the case when it comes to the motif of pain. The uniqueness of pain as an ontological phenomenon dictates the means and specificity of its verbalization.

Language affordances [16], an affected subject's verbal avowals and descriptions of unpleasant experiences ensure the linguistic dimension of pain, which otherwise would be nothing more than internalised highly subjective experience, invisible to others, hence the absence of signs for listeners to decode [26]. Due to this, the relation of language to pain is set through the distinction of private and shared experience. In Jackson's view (that is supportive of Wittgenstein's approach [26]) [12, p. 220], "pain, in a sense, is a language", while one can observe and recreate pain in the act of describing it and explaining it in a way to others.

Contrary to that opinion, Kugelmann claims that pain and the experience of pain are not dependable in the sufferer's rhetoric and exist regardless of their being verbalized or not. "Precisely because it is invisible, does everyone involved seek to reveal it." [17, p. 1668-1669]. This statement unveils a subjective nature of pain and questions it being a part of our socially perceived reality [18]. In support of the above, Scarry [21] stresses that physical pain is virtually inexpressible and "resists language" [19, p. 32].

The view of pain and our possibility to verbalize it are directly translated into the approach of recent studies of emotional concepts $[13,14,15,20,25]$. The concept of pain is manifested through a set of verbalized conceptual metaphors and metonymies of pain as well as conceptual prototypes of pain. The latter are often summarised in schemas, which are akin to the emotional reaction of a person experiencing pain and are of universal nature. Alongside conceptual metaphors of pain, three conceptual prototypes of pain have been introduced by Kövecses $[13,15]$. These include pain as an immediate response, pain as a long-lasting state, and pain as a routine response. Each prototype of pain has its own biological and psychological characteristics. Interestingly enough, actual semes and words, such as "hurt" or "pain", that signal or elude to understanding that the character is a subject to adverse physical or/and psychological pain, are often absent from the body of a fictional text, leaving out the keyword analysis from the methodological toolkit.

Similarly, the motif of pain unfolds in Ernest Hemingway's novel "For Whom the Bell Tolls" (1940). To observe that, let us consider a fragment below. The scene there is crucial to our research, since one of the main characters (Robert Jordan) is badly hurt and tries to convince his significant other (Maria) to proceed with their journey without him, seeing that his leg is broken and her not willing to abandon him on her own volition, e.g.:

[...] Robert Jordan spread the cloth with his hands and looked at the stretch of his thigh. Ten inches below the hip joint there was a pointed, purple swelling like a sharppeaked little tent and as he touched it with his fingers he could feel the snapped-off thigh bone tight against the skin. His leg was lying at an odd angle. [...]"Listen. We will not be going to Madrid - Then she started to cry. "No, guapa, don't," he said. "Listen. We will not go to Madrid now but I go always with thee wherever thou goest. Understand?" She said nothing and pushed her head against his cheek with her arms around him. "[...] He knew there was a great hurry and he was sweating very much, but this had to be said and understood. "Thou wilt go now, rabbit. But I go with thee. As long as there is one of us there is both of us. Do you understand?" [...] "Nay, rabbit. Listen. That people cannot do together. Each one must do it alone. But if thou goest then I go with thee. It is in that way that I go too. Thou wilt go now, I know. [...] Thou wilt go now for us both. "Surely," he said. "It is harder for thee. But I am thee also now." She said nothing. He looked at her and he was sweating heavily and he spoke now, trying harder to do something than he had ever tried in all his life. "Now you will go for us both," he said. "You must not be selfish, rabbit. [...]" She shook her head. "You are me now," he said. "Surely thou must feel it, rabbit." [...] "Truly thus I go too. I swear it to thee. " She said nothing. "Now you see it," he said. "Now I see it is clear. [...]" She had said nothing. "[...] Now you are going well and fast and far and we both go in thee. Now put thy hand here. Now put thy head down. Nay, put it down. That is right. Now I put my hand there. Good. [...] Now thou art obeying. Not me but us both. The me in thee. Now you go for us both. Truly. We both go in thee now. "[...] Now stand up and go and we both go. Stand up. See?" (FWBT, p. 462-463)

The excerpt contains two kinds of pain representations. The former one is a case of explicit depiction of pain - the author describes Robert's injury and the way it affects the character's physical (signs of perspiration and heavy breathing) and verbal capability (difficulty in speaking, namely, sentence forming). The other one is implied: along with Robert's broken leg, an internal conflict of two characters and an unfortunate result of the injury - the lovers' separation, are highlighted. Here the nature of pain is shown as ambiguous, e.g. "he spoke now, trying harder to do something than he had ever tried in all his life". Whether the main character finds it difficult to talk, enduring a great amount of pain, or suffers from the inevitable choice of letting go his loved one is open to the reader's interpretation.

The cognitive aspect of the analysis lies not only with the employment of the findings in studies on emotional concepts, but also in understanding of conceptual building of the storyworld [9] with the help of deictic expressions and its specifics when it is concerned with the motif of pain. The storyworld of the novel is set in the fictional Spain. In the scope of this research the motif of pain is defined as a) a sequence of signs and keywords that indicate pain or painful experiences; and b) a complex stock device traced throughout the whole story that marks an act of suffering, both physical and emotional. In view of the given definition the analysis presupposes four stages:

i) identifying keywords and semes that denote, indicate, or/and describe pain;

ii) reconstruing conceptual metaphors and metonymies of pain and defining their function in pain depiction;

iii) segmenting actions in the extract to analyse its proairectic elements; then investigating deictic expressions, type of focalization and the character's profiles; 
iv) analysis of the author's usage of Spanish in the extract and effects produced by doing so on the storyworld building of the novel; .

Lacking conventional keywords that indicate pain, e.g. "hurt", the excerpt contains a cluster of words that describe injury, which implies pain experience: "a pointed, purple swelling", "the snapped-off thigh bone", "[leg lying] at an odd angle" (dislocation due to a broken bone). Further indications of Robert being in intensified pain are linked to the word "sweating" which is recurrent in the extract. Interestingly enough, the emotional torment experienced by Maria opon seeing Rober's injury and underlying promise of a further separation is conveyed implicitly by the verbs of verbal and bodily action: "[she] started to cry", "said nothing", "pushed her head". These indirect verbal manifestations of pain through the descriptions of injury and its symptoms along with the post-shock of pain give rise to conceptual metonymies of pain: INJURY FOR PAIN, SWEATING FOR PAIN, CRY FOR SUFFERING. This way of indicating pain creates a sense of intimacy due to the readers' living through the main characters' experience of pain, as well as hinting that they may have no affordances to express what they are feeling in the way that would be sufficient and meaningful. The conceptual metaphor for Maria's emotional pain seems to be PAIN IS A SILENCER, as the woman is repeatedly fails to verbalize her pain of losing her partner, e.g. "she said nothing [...], she had said nothing [...] she shook her head" (FWBT, p. 462-463). Both conceptual metaphors and metonymies here serve as image-generating techniques that lay the ground for the motif of pain to unfold further.

As it has been previously mentioned, a motif is often understood as a narrative stock device that includes a set of agents, action/sequence of actions, locality and temporal phases. Respectively, the motif of pain contains a similar set of components with several alterations to it. So when it comes to the motif of pain, its agents are affected ones, the ones that suffer some sort of physical or emotional discomfort; the action or actions described are motivated by the cause of pain (e.g. a character shooting another one) or/and the actions an affected agent does or does not take to elevate this pain; the aspect of locality might be often given very little attention (unless it is pain-inducing, e.g. a torture chamber) since the solemn focus is placed on the character's pain experience that could be an isolating one; temporal phases might be either very rigid (if some specific physical trauma occurs) or blurred. This is especially important to take into account when speaking of the storyworld building in the novel and the predictable prevalence of the certain type/types of deictic markers. With the affected agent given a special importance in the motif's structure (in the case of the motif of pain) character's emotions and actions, they take to prevent or cope with pain, are vital for our analysis.

An overlap of emotional (the lovers' inevitable loss of each other) and physical pain of Robert's broken leg as well as the resultant tension serve as a functional canvas for the motif of pain unfolding, which is further exacerbated by a matrix of multilevel personal deixis [22, p. 4549]. In Figure 1 both Robert and Maria are affected agents, experiencing either physical or emotional inflictions. In the fragment under analysis both characters go through the emotional suffering (separation and loss of each other).
The use of the personal pronouns "us", "we" and the conjunction "both" create a particular union between the two characters: "Not me but us both. The me in thee. Now you go for us both". However, only Robert has an injury that will more than likely terminate his life since the group, which he belongs to, is being chased by the enemies. The juxtaposition of personal pronouns "you- me", "I - you", "I - thee" renders perceptual deixis of characters being physically farther apart from each other than ... [22, p. 4546]. Pain is, after all, a highly subjective experience, and in Robert's circumstances it is understood as the reason that might lead to death, which is portrayed as an alienating experience. This idea is emphasised by the demonstrative "that" in the cross-referential function (as in "That people cannot do together. Each one must do it alone"), used as a euphemism for death presented as a separating agent (see Figure 1).

Figure 1. Perceptual deixis in the fragment from "For Whom the Bell Tolls"

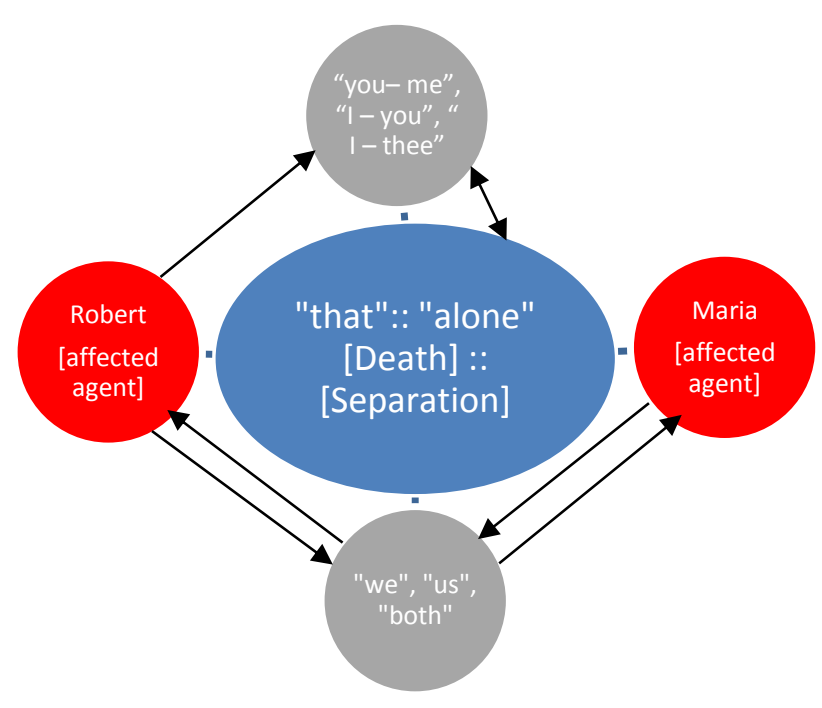

The duality provoked by the character's use of pronouns that either detach Maria and Robert ('you - me') from each other or bring them together ("we", "us", "both") implies, on the one hand, the end of Robert's physical existence and his experience of pain as an isolating and separating state that can hardly be expressed or understood by another. Thus, there is no immediate need for the "onlookers", hence Robert encourages Maria to escape without him. On the other hand, it points to a certain repudiation of the physical body and the metaphorical union (e.g.: "You are me now $\left.[. . .]^{\prime \prime}\right)$ with Maria that transcends the existential borderline, e.g.:

"You must not be selfish, rabbit. [...]" She shook her head. "You are me now," he said. "Surely thou must feel it, rabbit. " [...]"Truly thus I go too. I swear it to thee. " She said nothing. "Now you see it," he said. "Now I see it is clear. [...]"'"(FWBT, p. 463)

External focalization, since no characters' thoughts or feelings are manifested, which is especially true for Maria, further highlights the subjectivity of both characters' painful experience [7]. The author uses simultaneous mode of narration, where the story is unfolding at the moment it occurs with no narrational commentary, flash forwards or 
flashbacks, lack of the character's self-reflection. This results in a certain alienation of one action/event from another one: [Robert inspecting his injury] - \{no commentary about the pain he is experiencing $\}-$ [the injury description ] - \{no mentioning of its discomfort $\}-$ [a comment about Robert's leg lying at an odd angle]. The effect is strengthened by short brisk sentences that create a raged and abrupt tempo of the narrative unfolding: "That people cannot do together. Each one must do it alone. But if thou goest then I go with thee. It is in that way that I go too.". The storyworld in this case is conceptualised as a fragmented closed-in space with the main character's detached from the events around [9]. There is no mention of what other participants of the group, Robert and Maria were part of, are doing, nor there are auditory images that would occur naturally in the forest or gunshots of the characters' followers.

Spatial deictic expressions are almost obsolete in the scene which supports the overall blurred image of the surroundings where the characters actually are. The only expressions that imply some direction are "up" (as in "stand up" - vertical) and the implied horizontal vector of movement in "go" ("go away"). Both underpin the theme of "moving on" and "being set free" from the burden of pain. The heaviness that is conceptually associated with pain is first reinforced by Maria's posture ("put your head down") and then lifed ("stand up"). Temporal deixis expressed by the repetition of "now" strengthens the bond between two characters and shifts the attention away from Robert's grim future.

The setting of the storyworld of the novel is in the fictional Spain with Madrid, as a locus. That, along with the author's extensive usage of Spanish throughout the extract, is used to achieve believability of the storyworld, due to the immediate reader's reference to the existing historical background of the country, which in turn gives even stronger degree of realism not just to for the scenario, but for the pain depicted in the separate episode as well.

Consequently, we may conclude that the motif of pain might present itself in the narrative through a set of images and actions that revolve around a traumatic experience. In the fragment under analysis the set opens with the image of an injury (a broken leg) and its graphic and quite meticulous depiction which slows the pace of narration. Then the course of action unfolds into a brisk dialogue of the characters, being oblivious to the actions of other participants of the scene. The affected agents (Robert and Maria), their states (them being physical and emotional hurt), and the locality that presupposes a bounded space (the chase narrows the characters' options for escape, very little description of the actual scenery) with blurred temporal phases (there is no mention of how much time is gone) constitute the motif of pain that, as we have determined, operates on very scare verbal resources that facilitate locality and temporal phasing, which in the end yet again highlight the subjectivity, alienation, and internalization of pain experience.

\section{REFERENCES}

1. Bor D. The Ravenous Brain: How the New Science of Consciousness Explains Our Insatiable Search for Meaning / Daniel Bor. New York: Basic Books, 2012. - 334 p.

2. Boyd B. On the Origin of Stories: Evolution, Cognition, and Fiction / Brian Boyd. - Cambridge, MA: Belknap Press of Harvard University Press, 2009. - 540 p.

3. Cognitive Literary Science. Dialogues between Literature and Cognition / edited by Michael Burke and Emily T. Troscianko. - New York: Oxford University Press, 2017. - 370 p.

4. Edelman G. Second Nature: Brain Science and Human Knowledge / Gerald Edelman. - New Haven, CT: Yale University Press, 2006. $-204 \mathrm{p}$.

5. Fludernik M. An Introduction to Narratology / Monika Fludernik. - New York: Routledge, 2009. - 190 p.

6. Fukushima K. Neocognitron: A Self-organizing Neural Network Model for a Mechanism of Pattern Recognition Unaffected by Shift in Position / Kunihiko Fukushima // Biology. Cybernetics. 1980. - No. 36. - P. 193-202.

7. Genette G. Narrative Discourse. An Essay in Method / Gérard Genette. - Oxford: Blackwell, 1980. - 288 p.

8. Hawkins J. On Intelligence / J. Hawkins, S. Blakeslee. - New York: St. Martin's Press, 2005. - 98 p.

9. Herman D. Basic Elements of Narrative / David Herman. - Oxford: Blackwell, 2009. $-250 \mathrm{p}$.

10. Herman D. Storytelling and the Sciences of Mind / David Herman. - Cambridge: MIT Press, 2013. - 442 p.

11. Herman L. Handbook of Narrative Analysis / L. Herman, B. Vervaeck. - Lincoln and London: University of Nebraska Press, 1994. -244 p.

12. Jackson J. The Rashomon approach to dealing with chronic pain / Jean Jackson // Social Science and Medicine. - 1994. - No. 38. P. 823-833.

13. Kövesces Z. Metaphor and Emotion / Zoltan Kövesces. - Cambridge: Cambridge University Press, 2000. -242 p.

14. Kövesces Z. Metaphor. A Practical Introduction / Zoltan Kövesces. - Oxford: Oxford University Press, 2002. - 212 p.

15. Kövesces Z. Metaphors of Anger, Pride, and Love / Zoltan Kövesces. - Amsterdam: John Benjamins, 1986. -100 p.

16. Kress G. Multimodality. A Social Semiotic Approach to Contemporary Communication / G. Kress. - London: Routledge, 2010. P. 28-42.

17. Kugelmann R. Complaining about chronic pain / Robert Kugelmann // Social Science and Medicine. - 1999. - No. 49. - P. 1663 1676.

18. Kurzweil R. How to Create a Mind / Ray Kurzweil. - London: Viking, 2012. - $186 \mathrm{p}$.

19. Lascaratou C. The Language of Pain. Expression or Description?/Chryssoula Lascaratou. - Amsterdam/ Philadelphia: John Benjamins Publishing Company, 2007.-252p.

20. Rosch E.H. Cognitive representation of semantic categories / E.H. Rosch // Journal of Experimental Psychology: General. - 1975. No. 104. - P. 192-233.

21. Scarry E. The Body in Pain: The Making and Unmaking of the World / Elaine Scarry. - New York: Oxford University Press, 1985. $-390 \mathrm{p}$.

22. Stockwell P. Cognitive Poetics: An Introduction / Peter Stockwell. - London: Routledge, 2002. - 204 p.

23. Routledge Encyclopedia of Narrative Theory / edited by David Herman, Manfred Jahn and Marie-Laure Ryan. - New York: Routledge, 2005. - 934 p.

24. Varela F. J., Thompson E., Rosch E. The Embodied Mind: Cognitive Science and Human Experience / Varela Francisco J., Thompson Edward, \& Rosch Eleanor. - Cambridge, MA: MIT, 1991. $-120 \mathrm{p}$.

25. Wierzbicka A. Defining emotion concepts / Anna Wierzbicka // Cognitive Science. - 1992. - No. 16. - P. 539-581.

26. Wittgenstein L. Philosophical Investigations / Ludwig Wittgenstein. - Oxford: Basil Blackwell, 1989. - 322 p. 